\title{
Penguatan Ekonomi Pemuda Berbasis Kearifan Lokal di Kabupaten Aceh Besar
}

\author{
Akmal Saputra', Cut Irna Liyana ${ }^{2}$, Triyanto $^{3}$, Wardah Muharriyanti Siregar4, \\ Ikhsan $^{5}$, Vellayati Hajad ${ }^{6}$ Iwan Do'a Sempena ${ }^{7}$ \\ 123Jurusan Sosiologi, Universitas Teuku Umar \\ Email: akmalsaputra@utu.ac.id \\ Email: cutirnaliyana@utu.ac.id \\ Email: triyanto@utu.ac.id \\ 4 Jurusan Akuntansi, Universitas Teuku Umar \\ Email: wardah_muharriyanti@yahoo.com \\ 56Jurusan Ilmu Administrasi Negara, Universitas Teuku Umar \\ Email: ikhsan.baharudin@utu.ac.id \\ Email: vellayati.hajad@utu.ac.id \\ Jurusan Ilmu Komunikasi, Universitas Teuku Umar \\ Email: iwan_sempena@yahoo.com
}

Submitted: $05-11-2020$

Revised: $07-12-2020$

Accepted: $28-12-2020$

\section{Abstract}

This community service focuses on freshwater fish (catfish) cultivation. This community service is carried out on the basis of youth needs by involving youth or beneficiaries from planning to evaluation. This community service is carried out by paying attention to local wisdom in Gampong Pante Rawa Aceh Besar. The service method used is problem identification, coordination, planning, implementation, monitoring and evaluation. The results of this community service have had a good impact on the youth of Pante Rawa Aceh Besar village, both in economic, social and educational impacts. This community service provides income economically, builds social networks at the village and stakeholder level. This community service also provides new knowledge for youth about freshwater fish farming.

Keywords: Cultivation; Empowerment; Economic Strengthening; Local Wisdom.

\begin{abstract}
Abstrak
Pengabdian masyarakat ini fokus pada budidaya ikan air tawar (lele). Pengabdian masyarakat ini dilaksanakan atas dasar kebutuhan pemuda dengan melibatkan pemuda atau penerima manfaat mulai perencanaan hingga evaluasi. Pengabdian masyarakat ini dilaksanakan dengan memperhatikan kearifan lokal yang ada di Gampong Pante Rawa Aceh Besar. Metode pengabdian yang digunakan adalah identifikasi masalah, koordinasi, perencanaan, pelaksanaan, monitoring dan evaluasi. Hasil pengabdian masyarakat ini memberikan dampak yang baik bagi pemuda gampong Pante Rawa Aceh Besar, baik dampak ekonomi, sosial maupun dampak pendidikan. Pengabdian masyarakat ini memberikan pendapatan secara ekonomi, membangun jejaring sosial di tingkat gampong dan stakeholder, Pengabdian masyarakat ini juga memberikan pengetahuan yang baru bagi pemuda mengenai budidaya ikan air tawar.
\end{abstract}

Kata Kunci: Budidaya; Kearifan lokal; Pemberdayaan; Penguatan Ekonomi. 


\section{PENDAHULUAN}

Kegiatan pengabdian masyarakat ini merupakan salah satu program yang bertujuan untuk melakukan penguatan ekonomi bagi pemuda di gampong (desa) dengan memanfaatkan sumber daya alam dan kearifan lokal yang ada. Kegiatan ini merupakan sebuah program yang fokus pada budidaya ikan air tawar yaitu budidaya ikan lele.

Kegiatan ini dilakukan di Gampong Pante Rawa, Kabupaten Aceh Besar. Kegiatan ini dipilih atas dasar kondisi masyarakat khususnya pemuda di Gampong Pante Rawa mengalami persoalan dibidang ekonomi (pendapatan), sehingga menjadi penting bagaimana pemuda dapat diberdayakan secara ekonomi agar kebutuhan hidup dapat terpenuhi dengan baik.

Budi daya ikan lele menjadi salah satu program yang dipilih mengingat hasil analisis situasi menunjukkan program ini tepat dilakukan di Gampong Pante Rawa Aceh Besar. Gampong Pante Rawa terletak di pinggiran pegunungan yang jauh dari pesisir, di Gampong Pante Rawa terdapat areal persawahan dan rawa-rawa yang memiliki air yang cukup tanpa perlu adanya irigasi, kondisi alamnya juga tidak pernah mengalami masalah banjir. Atas dasar kondisi geografis itu, sehingga budidaya ikan air tawar dinilai tepat untuk dilakukan.

Pengabdian masyarakat ini menggunakan metode dan konsep pemberdayaan, tidak hanya sekedar memberikan bantuan yang bersifat sementara tanpa mengajak pemuda untuk berpartisipasi. Pemberdayaan masyarakat bermakna "menolong orang lain agar ia dapat menolong dirinya sendiri", Pemberdayaan masyarakat juga bermakna "kekuasaan", artinya masyarakat memiliki kuasa atas dirinya sendiri, pemberdayaan masyarakat memberikan sumberdaya, kesempatan, pengetahuan dan keterampilan untuk meningkatkan pengetahuan mereka agar menjadi mandiri, masyarakat bukanlah objek tetapi subjek dari program pemberdayaan masyarakat (Ife \& Tesoriero, 2008).

Pemberdayaan masyarakat juga bermakna setiap individu, organisasi, masyarakat menjadi ahli dan memahami masalah yang mereka sedang hadapi (Iswari, Indrayani, \& Suwena, 2019; Vina Salviana Darvina Soedarwo, Nurul Zuriah, Ratih Yuliati, 2017) .

Pemberdayaan masyarakat bukanlah metode baru dalam pendampingan masyarakat, metode ini telah banyak dilakukan dalam proses pendampingan masyarakat untuk menuju masyarakat yang 
mandiri terutama pada penguatan pemuda (Ogamba, 2018).

Pemberdayaan masyarakat merupakan salah satu upaya-upaya pengentasan kemiskinan, misalnya melalui ekonomi kreatif, pariwisata dan modal sosial (Alfrojems, 2019), Pemberdayaan masyarakat melalui budidaya ikan air tawar dan tidak hanya sekedar menjual bahan "mentah" saja namun menjadi bahan "jadi"(Iswari et al., 2019). Pemberdayaan masyarakat juga tidak hanya sekedar budidaya ikan air tawar saja, namun juga bagaimana memberikan stimulus kepada masyarakat agar dapat mengubah cara pandang mereka terhadap budidaya dan juga memberikan semangat untuk berwirausaha dan berpartisipasi (Iswadi, 2019).

Pemberdayaan masyarakat juga tidak hanya terfokus pada penguatan kapasitas dan pendayaan, namun juga ada proses penyadaran (Utami \& Khonitan, 2018). Pemberdayaan masyarakat juga dapat dilakukan dengan memanfaatkan BUMD (Badan Usaha Milik Desa) atau di Aceh disebut dengan BUMG (Badan Usaha Milik Gampong), pemberdayaan masyarakat yang berbasis komunitas ke pemberdayaan yang memanfaatkan sumberdaya milik bersama (BUMD) (Sidik, Nasution, \& Herawati, 2018).

\section{METODE PELAKSANAAN}

Ada lima metode yang digunakan dalam pengabdian masyarakat ini. Pertama, Identifikasi awal, kegiatan ini dilakukan untuk melakukan penilaian awal terhadap kondisi gampong yang akan menjadi target program. Kedua, Koordinasi, yaitu melakukan koordinasi dengan perangkat gampong, pemuda dan stakeholder (LSM-LPU) yang akan terlibat. Ketiga, Perencanaan, kegiatan ini direncanakan sesuai dengan hasil identifikasi awal dan hasil dari masukan-masukan perangkat gampong, pemuda dan stakeholder yang terlibat, perencanaan program disesuaikan dengan kebutuhan masyarakat. Keempat, Implementasi, pelaksanaan kegiatan dikhususkan bagi pemuda yang mengalami kerentanan secara ekonomi dan pemuda yang putus pendidikan. Tim pendamping memastikan kegiatan ini terlaksana sesuai dengan yang telah direncanakan. pada tahap ini proses partisipasi pemuda menjadi hal yang sangat penting dan utama, Kelima, monitoring dan evaluasi kegiatan.

\section{HASIL DAN PEMBAHASAN}

Program ini dilaksanakan di Gampong Pante Rawa Kecamatan Kuta Malaka, Kabupaten Aceh Besar pada akhir tahun 2013 yang lalu (Saputra, 2013). Program ini 
didukung oleh Kemenpora (Kementerian Pemuda dan Olah Raga) sebagai penyandang dana tunggal sebesar 50.000.000,- (lima puluh juta rupiah) dan bermitra dengan LPU Aceh (lembaga pengembang ummat), sebuah LSM lokal yang ada di Aceh Besar yang fokus pada program-program pendampingan masyarakat di Aceh (Saputra \& Liyana, 2020).

Dosen Universitas Teuku Umar terlibat dan berperan sebagai tim pendamping masyarakat yang bekerjasama dengan LPU Aceh. Peran tim pendamping ini mulai dari penilaian situasi hingga pada tahap monitoring dan evaluasi program. Program ini juga melibatkan ahli dibidangnya yang telah berpengalaman dibidang budidaya ikan air tawar.

Untuk mendampingi masyarakat khususnya pemuda ada beberapa langkah yang kami lakukan. Langkah-langkah yang kami lakukan mulai dari identifikasi masalah, koordinasi, perencanaan, implementasi, proses, monitoring dan evaluasi.

Identifikasi situasi atau penilaian awal. Program pengabdian ini fokus pada program penguatan pemuda untuk meningkatkan taraf ekonomi pemuda menjadi lebih baik. Pada program pengabdian masyarakat ini, kami sebagai tim pendamping sangat mengutamakan proses dan partisipasi pemuda. Program ini dijalankan sesuai dengan kebutuhan masyarakat, bukan program yang lahir dari pikiran dan keinginan tim pendamping sendiri, oleh karena itu identifikasi situasi menjadi salah satu hal yang penting untuk menilai situasi yang ada di lokasi sasaran.

Adapun alasan memilih pemuda dikarenakan, Pertama, pemuda secara umur dan tenaga masih sangat produktif. Kedua, pemuda masih mampu untuk bekerja secara maksimal. Ketiga, pemuda merupakan harapan bangsa, jika pemuda kreatif dan inovatif maka gampong yang merupakan unit terkecil dari administrasi pemerintahan akan mengalami perkembangan dan kemajuan yang sangat baik.

Langkah pertama yang dilakukan oleh tim pendamping adalah identifikasi situasi, isu atau masalah. Identifikasi yang kami lakukan adalah, Pertama, mencari data jumlah penduduk di lokasi target kegiatan, mendata jumlah pemuda yang mengalami kerentanan secara ekonomi atau pemuda yang putus pendidikan, mendata informasi tentang mata pencaharian masyarakat termasuk kondisi sosial dan kebiasaan para pemuda digampong.

Temuan awal tim menunjukkan jumlah pemuda yang rentan terhadap ekonomi dan juga putus sekolah dinilai cukup tinggi, kebiasaan mereka saat itu adalah mengandalkan

mata 
pencahariannya dirawa-rawa dan sawah dengan mengandalkan kondisi alam yang ada.

Koordinasi, kegiatan berikutnya adalah melakukan koordinasi dengan perangkat gampong (desa), pemuda dan stakeholder yang terlibat dalam program ini. Koordinasi dilakukan dengan cara musyawarah di Meunasah gampong (pusat kegiatan di desa dan kantor desa).

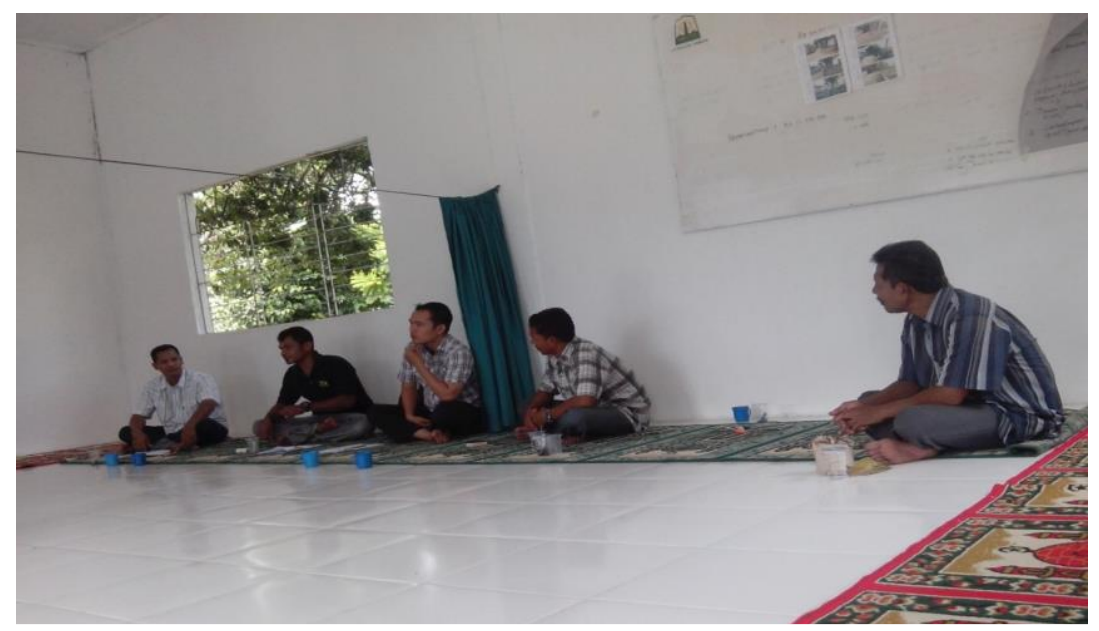

Gambar 1. Koordinasi dan musyawarah dengan perangkat gampong, pemuda dan stake holder di meunasah

Dalam musyarawarah ini kami menyampaikan sekaligus mendiskusikan dengan perangkat gampong, pemuda dan stakeholder, terkait dengan temuan dan penilaian awal yang telah kami lakukan secara bersama di gampong lokasi pengabdian.

Temuan kami menunjukkan saat ini pemuda di gampong Pante Rawa memiliki tingkat kerentanan yang cukup tinggi terhadap ekonomi, hal ini dipengaruhi oleh kondisi pendidikan yang tidak merata. Saat ini banyak pemuda yang putus pendidikan atau tidak melanjutkan pendidikan ke jenjang yang lebih tinggi.
Selain itu, kurang mendapatkan perhatian dari pengambil kebijakan dan juga kurang advokasi dari pemerintah gampong ke pemerintah daerah, sehingga berdampak pada kerentanan ekonomi pada masyarakat termasuk pemuda. Selama ini tidak usahausaha yang kreatif apalagi inovatif, selama ini tidak tim pendamping yang mencoba menggali keahlian/skill pemuda yang ada di gampong.

Atas dasar hasil analisis tim pendamping menunjukkan bahwa perlu diambil langkah-langkah yang tepat untuk menyelesaikan masalah sosial dan ekonomi yang ada. Tim 
pendamping juga menemukan bahwa, lokasi Gampong Pante Rawa memiliki keunggulan secara geografis. Gampong ini berada di daerah pinggir pegunungan dan memiliki ketersediaan air yang sangat baik. Gampong ini terdapat rawa-rawa dan areal persawahan yang tidak memerlukan irigasi dan sampai saat ini belum pernah terjadi kekeringan.

Tim pendamping kemudian mencoba mendiskusikan kepada masyarakat terutama pemuda dengan mengajak mereka untuk mendiskusikan program apa yang tepat untuk dilakukan di Gampong Pante Rawa sesuai dengan kondisi sosial, ekonomi dan mata pencaharian selama ini dan kondisi geografis yang ada.

Atas diskusi antara perangkat gampong, pemuda, tim pendamping dan stakeholder yang terlibat, kemudian secara bersama kami memutuskan untuk melakukan kegiatan budidaya ikan air tawar yaitu budidaya ikan lele sangkuriang.

Memilih budidaya ikan air tawar tentu tidak hanya sekedar alasan alam yang mendukung atau kondisi pemuda benar-benar membutuhkan unit usaha, tetapi juga membaca situasi pasar saat ini yang membutuhkan pasokan ikan lele yang cukup tinggi.

Aceh pasca konflik dan tsunami menjadi daerah target wisata yang menarik, selain wisata gempa dan tsunami, wisata konflik, wisata sejarah masa penjajahan, wisata alam, baik wisata pegunungan dan juga pesisir. Kuliner menjadi salah satu pendukung bahkan menjadi wisata utama yaitu wisata kuliner.

Ikan air tawar khususnya lele menjadi komoditi yang penting untuk mendukung wisata di Aceh. Permintaan ikan lele cukup tinggi di pasar, saat ini warung-warung atau pengusaha kuliner mengalami kekurangan pasokan ikan lele, sedangkan permintaan masyarakat sangat tinggi.

Kegiatan budidaya ikan air tawar ini pada dasarnya sesuatu yang baru bagi pemuda di gampong Pante Rawa, selama ini mereka tidak memiliki pengalaman dibidang ini, selama ini mereka bermatapencaharian sebagai petani, peternak, pekebun bahkan dibidang jasa (tukang dan pekerja kasar lainnya).

Selama ini jika mereka ingin mengkonsumsi ikan air tawar, mereka masih mengandalkan ikan yang tersedia di alam dengan cara memasang jaring atau memancing di rawa-rawa dan sawah.

Setelah mendapatkan kesepakatan terkait program apa yang akan dilaksanakan, langkah berikutnya adalah membuat perencanaan untuk mengimplementasi kegiatan pendampingan. Saat perencanaan tim pendamping melibatkan pemuda, perangkat gampong, dan 
tim LPU. Tanpa perencanaan yang matang tentu saja merencanakan kegagalan.

Kegiatan-kegiatan yang direncanakan adalah pelatihan atau workshop tentang budidaya ikan air tawar yang melibatkan ahli dibidangnya, kemudian pembuatan kolam tanah dan juga kolam jaring, persediaan peralatan dan perlengkapan termasuk pembelanjaan kebutuhankebutuhan untuk budidaya, pembelian bibit unggul, pemasaran hasil budidaya dan perhitungan laba dan rugi.

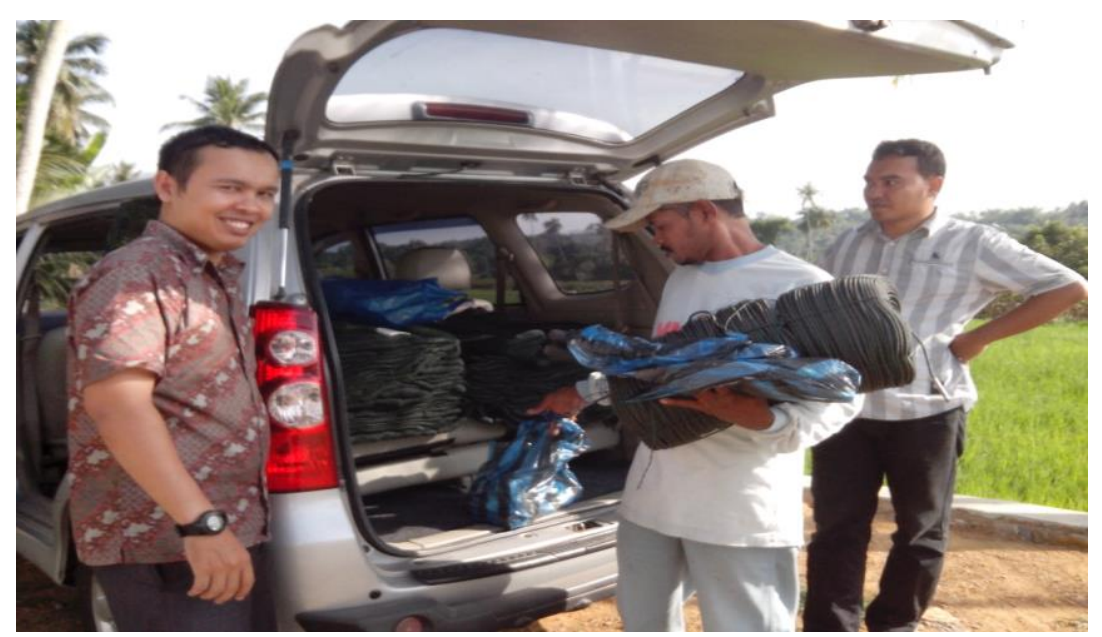

Gambar 2. Serah terima perlengkapan budi daya ke pemuda

Kebutuhan-kebutuhan ini di diskusikan dengan tim ahli, pemuda dan juga perangkat gampong. Beberapa perlengkapan untuk pembuatan kolam tersedia di alam yang tersedia digampong, misalnya kayu, atap rumbia, papan dan juga bambu.

Tahap implementasi, pada tahap ini langkah yang pertama dilakukan adalah melaksanakan pelatihan atau workshop tentang teknik budidaya ikan lele (pemberian pakan dan masa panen), pembuatan kolam jaring dan kolam tanah, perhitungan laba dan rugi dan juga teknik pemasaran.
Pembuatan kolam jaring dan kolam tanah dibangun oleh pemuda sendiri yang didampingi oleh tim pendamping. Tim pendamping membuat empat kelompok pemuda untuk budidaya ikan lele, masingmasing kelompok diberikan satu kolam.

Proses pemeliharaannya diberikan sepenuhnya kepada pemuda dengan tetap melakukan pendampingan, tim pendamping melakukan proses pendampingan terkait pertumbuhan ikan lele.

Selanjutnya tim pendamping bersama LPU, pemuda dan perangkat gampong membangun 
jejaring dengan pasar, tidak hanya dengan pasar rakyat, tetapi juga warung-warung atau pengusaha kuliner agar hasil panen dapat ditampung oleh mereka.

Kegiatan ini terus dilakukan monitoring guna untuk memastikan bagaimana proses pemeliharaan yang sedang berlangsung, termasuk pemantauan pemberian pakan, kondisi air dan kondisi cuaca, pemantauan interaksi sosial didalam kelompok pemuda dan antar kelompok pemuda. bagaimana pemuda membangun koordinasi dengan perangkat gampong dan juga bagaimana pemuda melakukan kerjasama dengan pengusaha kuliner dan pasar agar hasil panen nantinya dapat segera dipasarkan.

Monitoring penting dilakukan, guna mengambil langkah-langkah yang tepat ketika ada hal-hal yang tidak sesuai dengan yang direncanakan atau ada hal-hal yang terjadi diluar dugaan. Sejauh pelaksanaan kegiatan budidaya lele ini tidak ada terjadi sesuatu hal yang dapat merugikan secara ekonomi dan sosial

Kegiatan ini juga dilakukan evaluasi proses, guna memastikan sinkronisasi antara program yang telah direncanakan (perencanaan) dan implementasi program. Pastinya tidak semua yang telah direncanakan dapat berjalan sesuai dengan harapan, karena kegiatan pengabdian baru pertama sekali dilaksanakan dan kelompok pemuda juga belum punya pengalaman sebelumya.

Pasca panen pertama, tim pendamping bersama kelompok pemuda, perangkat gampong dan juga LSM LPU duduk bersama untuk melakukan evaluasi program yang selama ini telah dijalankan selama tiga bulan penuh. Diskusi diarahkan apa yang menjadi kendala dan hambatan selama program berjalan.

Temuan lapangan menunjukkan tidak ada kendala yang berarti, hanya saja pemuda sebagai pelaku usaha masih pada tahap belajar dan perdana melakukan program budidaya lele, sehingga pendamping terus melakukan pendampingan dan monitoring agar prosesnya dapat berjalan dengan baik.

Pada pertemuan evaluasi ini juga dibahas mengenai keberlanjutan program budidaya, membahas dan mendiskusikan kekurangan dan kendala selama program berlangsung diharapkan tidak kembali terjadi pada saat program kedua dijalankan. Pada pertemuan ini juga didiskusikan hasil panen dan pembagian keuntungan setelah dipotong modal awal yang telah diinvestasikan. Modal awal itu kemudian akan diinvestasikan kembali untuk budidaya tahap kedua.

Output (hasil), kegiatan budidaya ini memberikan hasil 
yang baik secara ekonomi, salah satunya ada menambah income (pendapatan) bagi pemuda di gampong pante rawa. Panen ikan lele dapat dilakukan paling maksimal pada bulan ke tiga semenjak pelepasan benih ikan lele.

Outcome (dampak), kegiatan ini memberikan dampak ekonomi yang baik bagi pemuda terutama menambah pendapatan jika program ini terus dilanjutkan (sustainable). Program budidaya ini juga memberikan dampak yang baik bagi proses belajar dan pembelajaran bagi pemuda, mendapatkan ilmu dan pengetahuan baru bagi pemuda sekaligus ilmu dan pengetahuan ini dapat ditransfer kepada pemudapemuda yang lain.

Program budidaya ini telah memberikan manfaat dan dampak yang baik secara sosial dan ekonomi bagi pemuda gampong pante rawa.

\section{PENUTUP}

Pengabdian masyarakat ini telah memberikan dampak yang baik bagi pemuda Gampong Pante Rawa Aceh Besar. Pengabdian masyarakat ini tidak hanya memberikan dampak secara ekonomi bagi pemuda, namun juga memberikan dampak sosial bagi pemuda gampong Pante Rawa Aceh Besar.

Pemuda dapat membangun jejaring sosial yang baik dengan pengusaha, dapat membangun
Secara sosial telah memberikan pembelajaran yang penting, bahwa alam jika dikelola dengan baik dan tidak dicemar atau tercemar akan memberikan manfaat yang luar biasa bagi manusia.

Dampak sosial lainnya membangun interaksi sosial yang baik antara pemuda gampong, perangkat gampong, masyarakat umum dan tim pendamping sekaligus membangun jejaring sosial dan bisnis dengan pengusaha terutama pengusaha warung kuliner dan pasar. Jejaring bisnis dengan pengusaha menjadi hal yang sangat penting dengan harapan pemuda gampong kedepannya dapat mengembangkan unit-unit usaha yang lain yang dapat memberikan income (pendapatan) secara ekonomi dan sekaligus dapat memajukan gampong pante rawa kjhususnya.

interaksi sosial sesama pemuda, perangkat gampong dan juga stakeholder lainnya. Jejaring sosial yang telah terbentuk dapat membantu mereka untuk mengembangkan usahausaha/bisnis dibidang lainnya untuk mendukung perekonomian secara individual dan gampong.

Pengabdian masyarakat ini juga memberikan pengetahuan baru bagi pemuda Gampong Pante Rawa tentang bagaimana melakukan budidaya ikan air tawar yang 
sebelumnya mereka belum punya pengetahuan dan pengalaman sama sekali.

\section{DAFTAR PUSTAKA}

Alfrojems. (2019). Pengentasan

Kemiskinan Perdesaan Melalui

Pengembangan Ekonomi

Kreatif, Pariwisata dan Modal

Sosial. Sosio Informa, 5(2), 113-

127. Retrieved from

https://ejournal.kemsos.go.id/ index.php/Sosioinforma/articl e/view/1752/994

Ife, J., \& Tesoriero, F. (2008).

Community Development;

Alternatif Pengembangan

Masyarakat di Era Globalisasi.

Yogyakarta: Pustaka Pelajar.

Iswadi. (2019). Pemberdayaan

Masyarakat Melalui Pembinaan

Kelompok Perikanan Dalam

Meningkatkan Kesejahteraan

Masyarakat. Jurnal At-Taghyir,

2(1), 1-13.

https:/ / doi.org/https:/ / doi.or

g/10.24952/taghyir.v2i1.1971

Iswari, I. G. A. Y., Indrayani, L., \&

Suwena, K. R. (2019).

Pemberdayaan Masyarakat

Pesisir dalam Upaya

Meningkatkan Ekonomi di

Dusun Pangkung Dedari, Desa

Melaya, Kecamatan Melaya.

Jurnal Pendidikan Ekonomi, 11(2), 509-516.

https://doi.org/http://dx.doi.

org/10.23887/jjpe.v11i2.21550

Ogamba, I. K. (2018). Millennials

Empowerment: Youth

Entrepreneurship for

Sustainable Development.

World Journal of
Entrepreneurship, Management

and Sustainable Development.

https://doi.org/10.1108/WJE

MSD-05-2018-0048

Saputra, A. (2013). Penguatan

Pemuda Melalui Pengembangan

Usaha Produktif (Budidaya Ikan

Air Tawar Lele). Aceh Besar.

Saputra, A., \& Liyana, C. I. (2020).

Penguatan Sentra

Kewirausahaan Pemuda

Gampong Pante Rawa Aceh

Besar Melalui Program

Inkubator Bisnis Kemenpora.

Public Policy, 6(1), 7-12.

https:/ / doi.org/https:/ / doi.or

g/10.35308/jpp.v6i1.1724

Sidik, F., Nasution, F. G. A., \&

Herawati. (2018).

Pemberdayaan Masyarakat

Desa Menggunakan Badan

Usaha Milik Desa: Desa

Ponggok dan Kritik Terhadap

Prestasi "Terbaik Nasional."

Jurnal Pemikiran Sosiologi, 5(2),

80-107.

https://doi.org/https://doi.or

g/10.22146/jps.v5i2.44636

Utami, B. N., \& Khonitan, D. (2018).

Pemberdayaan Masyarakat

Berbasis "Social

Entrepreneurship" Bidang

Pertanian dan Peternakan:

Studi Kasus Desa Bukit

Langkap Kabupaten Lingga,

Kepulauan Riau. Jurnal

Pemikiran Sosiologi, 5(2), 126-

147.

https:/ / doi.org/https:/ / doi.or

g/10.22146/jps.v5i2.44638

Vina Salviana Darvina Soedarwo,

Nurul Zuriah, Ratih Yuliati, S.

(2017). Pemberdayaan

Masyarakat melalui pendidikan 
non formal Berbasis Potensi

Lokal Dalam Membangun Desa

Wisata Adat. Jurnal Sosiologi

Pendidikan Humanis, 2(2), 96-

102.

https:/ / doi.org/http:/ / dx.doi.

org/10.17977/um021v2i22017p

096 